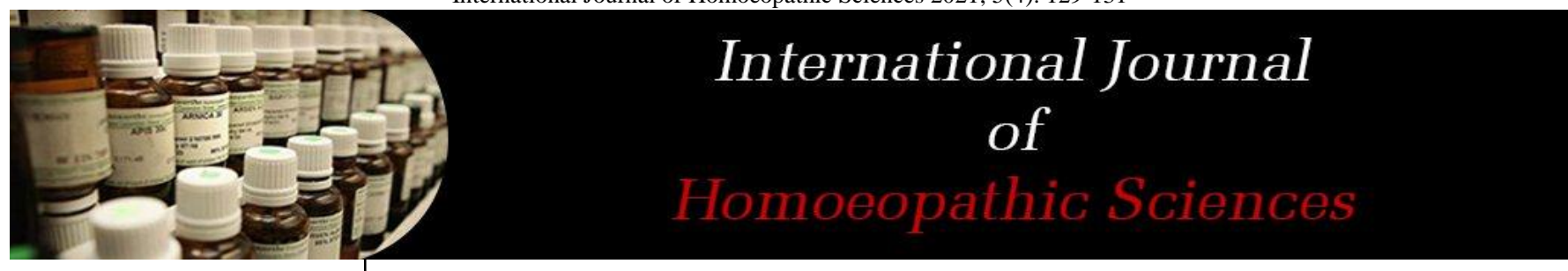

E-ISSN: $2616-4493$ P-ISSN: 2616-4485 www.homoeopathicjournal.com IJHS 2021; 5(4): 129-131 Received: 20-08-2021 Accepted: 24-09-2021

Ahamed Mohideen

Department of Paediatrics, Sarada Krishna Homoeopathic Medical College,

Kulasekharam, Tamil Nadu, India

\section{PR Sisir}

Department of Paediatrics, Sarada Krishna Homoeopathic Medical College,

Kulasekharam, Tamil Nadu, India
Corresponding Author: Ahamed Mohideen Dept. of Paediatrics, Sarada Krishna Homoeopathic Medical College, Kulasekharam, Tamil Nadu, India

\title{
Combating mobile phone addiction in children through homoeopathy
}

Ahamed Mohideen AT and PR Sisir

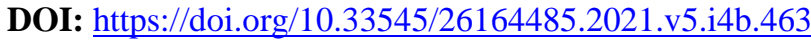

Abstract

The amount of time that the children spend on mobile phones has been increased drastically, added to the development of applications, learning features, gaming had made children more vulnerable to use more time. When speaking about safe and efficient way of treatment in managing such problems, Homoeopathy has an upper hand due to its individualistic and holistic approach. So, this study is mainly concentrating to determine the efficacy of homoeopathic medicines in management of mobile phone addiction in children. A sample of 15 cases screened and diagnosed with Problematic Mobile Phone Use Questionnaire (modified) to have mobile phone addiction is taken from the hospital in Kulasekharam. After analyzing for a period of time, 73\% (11 cases) showed marked improvement, followed by slight improvement in 7\% (1 case) and no improvement in 20\% (3 cases). Hence, Homoeopathy found to be effective in controlling mobile phone addiction in children.

Keywords: Addiction, children, homoeopathy, mobile phones, questionnaire

\section{Introduction}

Mobile phones initially used for communication purpose, but as days progressed it has revolutionized in every aspect in one's life where we can able to access any data or information at any corner of the world in our fingertips. Smart phone use has surged during the last decade especially in developing nations like India. Early researches portrayed its positive outcomes. To be more particular, it has often been argued that smart phones gives access to communication without moving from place to place by confined at one spot ${ }^{[1]}$.

Mobile phone dependence (MPD)/addiction refers to an increased indulgence to activities associated with mobile phones, amid eagerness and a robust and continuous dependence on mobile phones, which ends up in loss of self-control and compromised psychological and social functioning among individuals ${ }^{[2]}$. Due to the increased popularity and the amount of time spent on their smart phones, excessive usage had become one of the emerging widespread behavioral addictions.

Previous studies reveal that this addiction had caused variable mental problems in teenagers such as depression, suicidal ideas as well as physical problems like blurring of vision, headache, neck pain and disturbances in sleep. It also been found there is financial and social problems like suspension from school associated with this addiction especially in adolescent period $^{[3]}$.

Whereas, this addiction is not alone caused only by the children, involvement of parents also plays a vital part in it. So, this study is mainly concentrating to determine the efficacy of homoeopathic medicines in the management of mobile addiction in children.

\section{Materials and Methods}

It is a clinical study with pre and post assessment. 15 cases of Mobile Phone Addiction were taken from the college OPD of Sarada Krishna Homoeopathic Medical College. Screening was done by using Problematic Mobile Phone Use Questionnaire (PMPUQ Modified). Data was collected according to SKHMC case format.

\section{Inclusion Criteria}

Patients of age group between 2-17 years of age who are diagnosed to have Mobile Phone addiction. Children of both sexes 


\section{Exclusion Criteria}

Patients below 2 yrs and above 17 years of age. Patients of unwilling parents.

\section{Intervention}

Medicine was selected based on the available totality of symptoms of the child. Potency was selected according to susceptibility of the patient. The outcome of the study is assessed by the same questionnaire used for screening i.e., Problematic Mobile Phone Use Questionnaire (PMPUQ). Added to it, overall performance of the patients is also assessed. Statistical data is done by paired t test for pre and post score assessment.

\section{Result}

Pre \& Post Addiction Scores

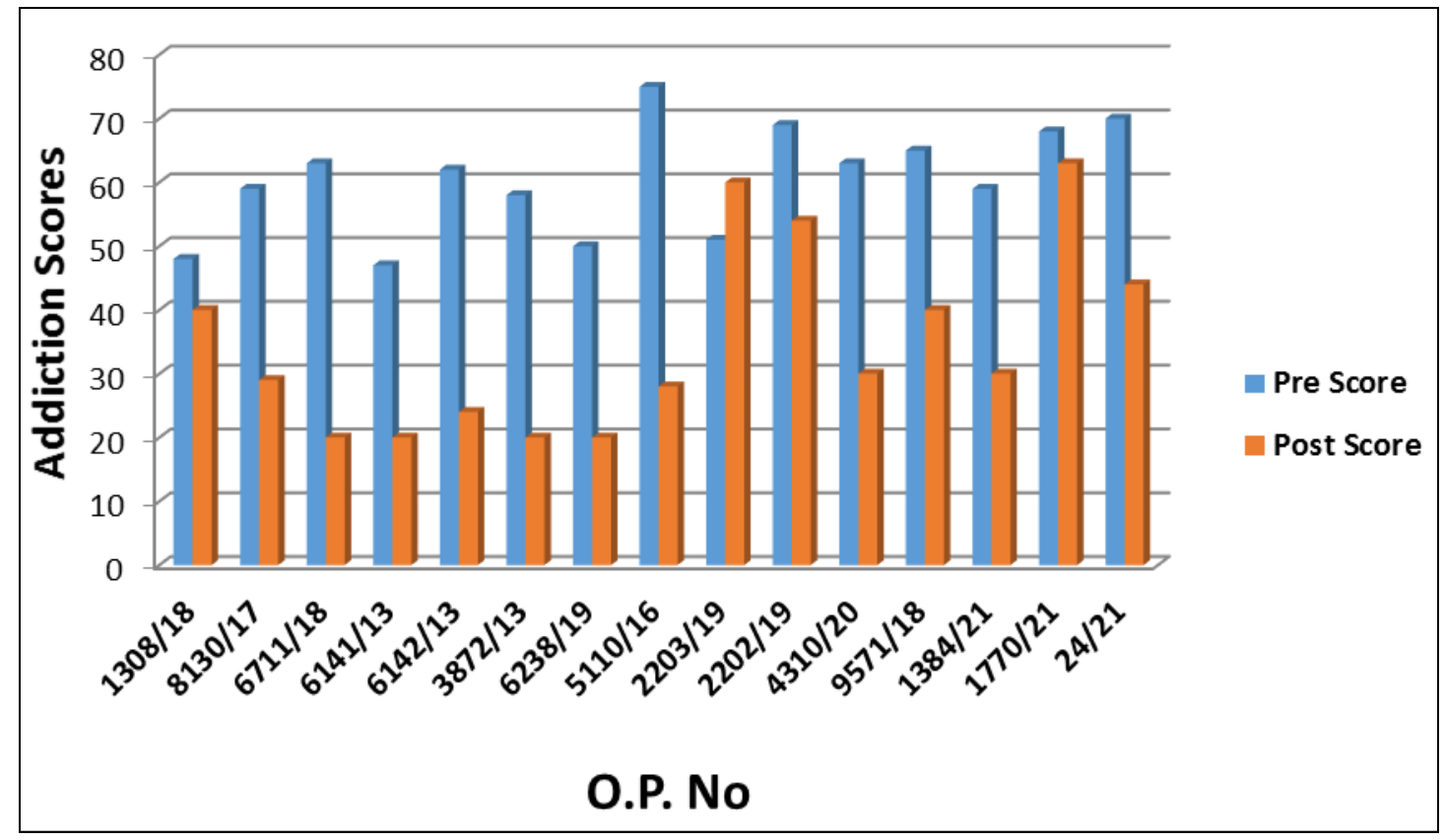

Fig 1: Pre and Post Assessment

Distribution of cases according to improvement

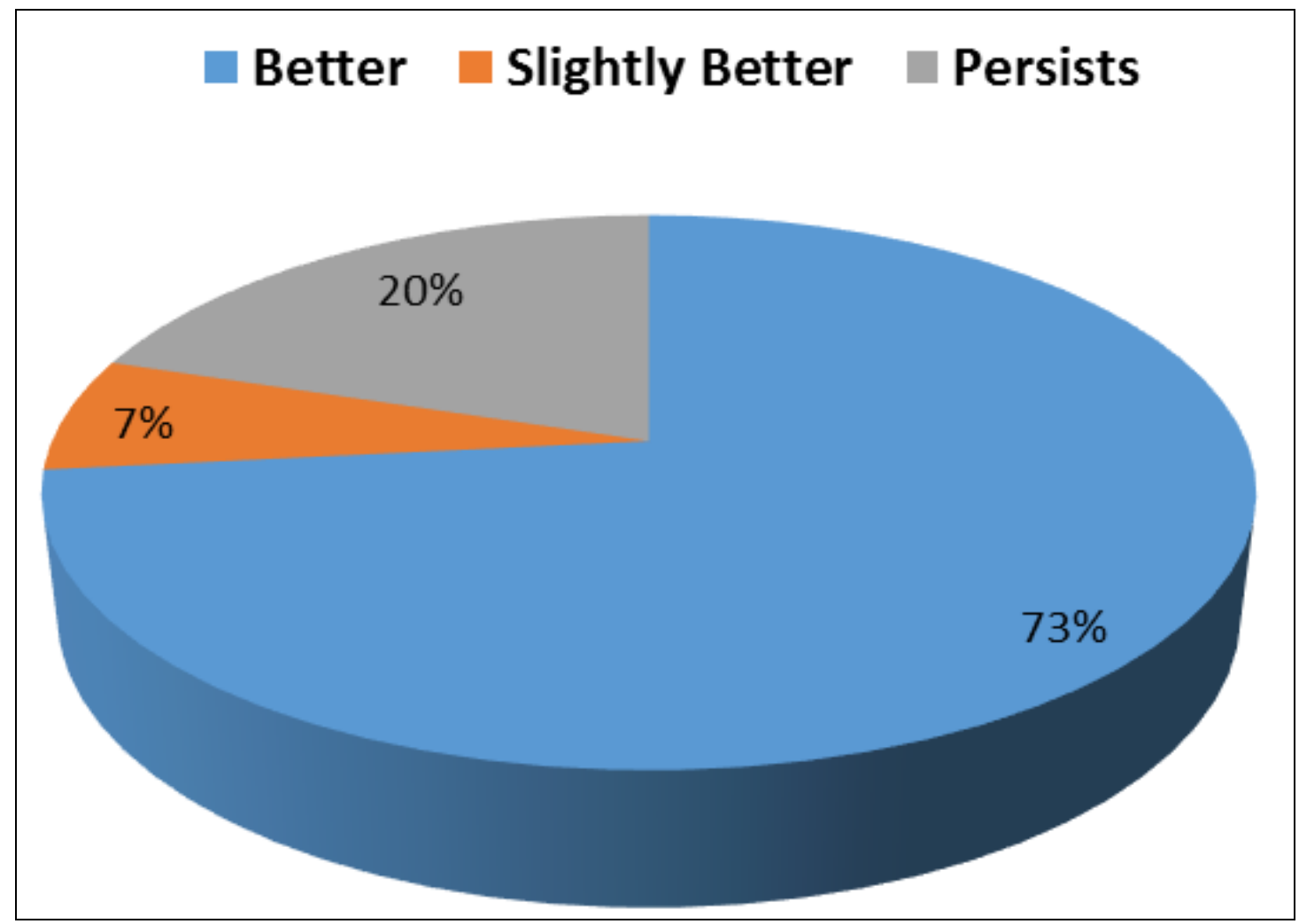

Fig 2: Inference 


\section{Distribution of cases according to medicine prescribed}

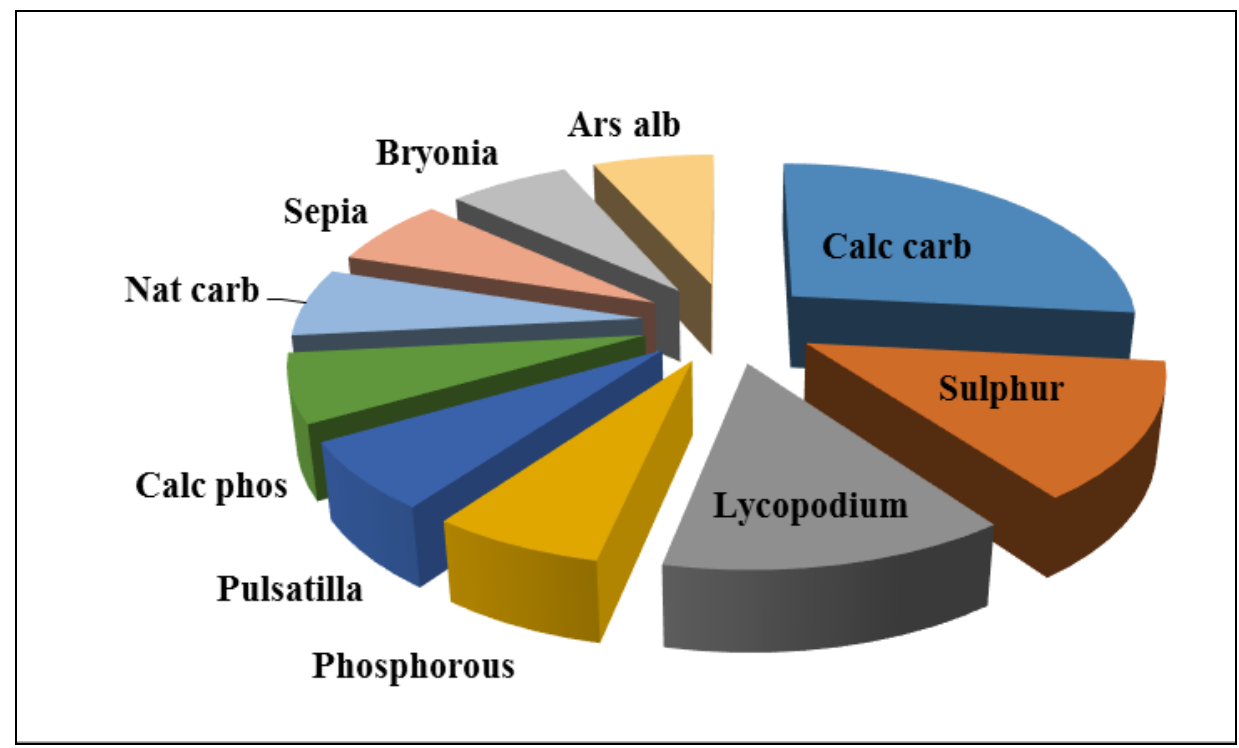

Fig 3: Distribution of medicine prescribed

\section{Statistics}

The mean value of post score (34.8) is lesser than the pre score (60.46) indicating marked improvement after homoeopathic medicines. The p-value equals 0.0000128 , $(\mathrm{p}(\mathrm{x} \leq \mathrm{T})=0.000006399)$. It means that the chance of type I error (rejecting a correct $\mathrm{H}_{0}$ ) is small: $0.0000128(0.0013 \%)$. The smaller the $\mathrm{p}$-value the more it supports $\mathrm{H}_{1}$. Since $\mathrm{p}$ value $<\alpha, \mathrm{H}_{0}$ is rejected.

\section{Conclusion}

After a period of time, $73 \%$ (11 cases) showed marked improvement, followed by slight improvement in $7 \%$ (1 case) and no improvement in $20 \%$ (3 cases). In this study, the medicine which is given most was Calc Carb to 4 cases. This is followed by Sulphur and Lycopodium with 2 cases each. The other medicines prescribed was Phosphorous, Pulsatilla, Calc Phos, Nat carb, Sepia, Ars alb and Bryonia. There is significant improvement in pre and post dependency scores, thereby rejecting the Null Hypothesis. Hence, it is thereby evident that homoeopathic medicines are found effective in combating mobile phone addiction in children.

\section{References}

1. Billieux J. Problematic use of the mobile phone: a literature review and a pathways model. Current Psychiatry Reviews. 2012;8(4):299-307.

2. Li X, Hao C. The relationship between parental attachment and mobile phone dependence among Chinese rural adolescents: The role of alexithymia and mindfulness. Frontiers in psychology. 2019;10:598.

3. Kim HH, Chun J. Is the relationship between parental abuse and mobile phone dependency (MPD) contingent across neighborhood characteristics? A multilevel analysis of Korean Children and Youth Panel Survey. PloS one. 2018;13(5):e0196824.

4. Panova T. How ICTs can influence psychological wellbeing: an analysis of uses and addiction potential (Doctoral dissertation, Universitas Ramon Llull).

5. Hosokawa R, Katsura T. Association between mobile technology use and child adjustment in early elementary school age. PloS one. 201825;13(7):e0199959.

6. Plowman L, McPake J, Stephen C. The technologisation of childhood? Young children and technology in the home. Children \& Society 2010;24(1):63-74.

7. Kabali HK, Irigoyen MM, Nunez-Davis R, Budacki JG, Mohanty SH, Leister KP, Bonner RL. Exposure and use of mobile media devices by young children. Pediatrics 2015;136(6):1044-50. 